$5-1-2012$

\title{
A Study on Underwriting Cycle of Property Insurance Industry of China
}

\author{
Lin Zhang \\ College of Hunan University, Changsha Hunan Province, China \\ Linjuan Tang \\ College of Hunan University, Changsha Hunan Province, China
}

Follow this and additional works at: http://digitalcommons.wayne.edu/jmasm

Part of the Applied Statistics Commons, Social and Behavioral Sciences Commons, and the Statistical Theory Commons

\section{Recommended Citation}

Zhang, Lin and Tang, Linjuan (2012) "A Study on Underwriting Cycle of Property Insurance Industry of China," Journal of Modern Applied Statistical Methods: Vol. 11 : Iss. 1 , Article 23.

DOI: $10.22237 /$ jmasm/1335846120

Available at: http://digitalcommons.wayne.edu/jmasm/vol11/iss1/23

This Regular Article is brought to you for free and open access by the Open Access Journals at DigitalCommons@WayneState. It has been accepted for inclusion in Journal of Modern Applied Statistical Methods by an authorized editor of DigitalCommons@WayneState. 


\title{
A Study on Underwriting Cycle of Property Insurance Industry of China
}

\author{
Lin Zhang Linjuan Tang \\ College of Hunan University, \\ Changsha Hunan Province, China
}

Methods in underwriting cycle research are compared. A second-order autoregressive model, which includes structural transition and Christiano-Fitzgerald (CF) Filter method, is used to analyze China's underwriting cycle with annual property insurance loss ratio data from 1982 to 2008. Results show that the underwriting cycle is 11-12 years and, from the phase of underwriting cycle, management suggestions about underwriting cycle phenomenon are provided.

Key words: Underwriting cycle, property insurance, second-order autoregressive model, CF filter, structural transition.

\begin{abstract}
Introduction
An underwriting cycle refers to a period phenomenon of underwriting profit that fluctuates over time. A comprehensive underwriting cycle moves through four stages: mature hard market, immature soft market, mature soft market and immature hard market. As a specific phenomenon of the property insurance industry, the underwriting cycle has a significant impact. The phenomenon of underwriting cycles penetrates into all aspects of business of insurance companies and influences product pricing, claims payments, marketing strategy decisions and reserve calculations. Ernst \& Young (2009) lists the future top ten risks of the Chinese insurance industry in their Annual Report of Insurance Industry Operating Risk in China Market. They state that regulatory intervention, underwriting cycle management and climate change-among others - will
\end{abstract}

Lin Zhang is a Professor in the department of Finance and Statistics and is the Director of the Insurance Institute of China. She is a Fellow member of the Actuaries Association of China. Her research interests include non-life actuarial science. Email her at: lindazhang0203@126.com. Linjuan Tang is a student in the department of Finance. Email her at: tangljyouyou@163.com. become major risk factors for the Chinese insurance industry in the future, and that the underwriting cycle is the most important among the various risk factors. For this reason, research into property insurance underwriting cycles is particularly important. Although some professionals have studied underwriting cycles of property insurance, there is not a generally accepted empirical result regarding underwriting cycles.

Underwriting cycles were proposed by a broker company in the United States. Venezian (1985) proofed the existence of underwriting cycles for the property insurance industry, and Cummins and Outreville (1987) confirmed their existence in insurance markets outside of the U.S.A. Chen (1997) found the underwriting cycle existed in Asian emerging markets (including Japan, Singapore and Malaysia); he also notes that, even if there no underwriting cycle of whole non-life insurance industry exists in an individual country, there is an underwriting cycle phenomenon for some business lines, such as property insurance in Korea and motor insurance in Chinese Taipei.

In China, there have been a few studies on the underwriting cycle. Cai (2005) introduced the principle of an underwriting cycle in the world, his research focuses on insurance supply and demand. Wang and Shi (2006) used a second order autoregressive model with simple loss ratio data and concluded that there was no underwriting cycle in the Chinese property 


\section{UNDERWRITING CYCLE OF PROPERTY INSURANCE INDUSTRY OF CHINA}

insurance industry. However, they recognized there was an underwriting cycle in the motor insurance business line that is about 6 years. A similar study was conducted by Zhang and Zhu (2007). Li and Li (2010) used a filter method and simple loss ratio data and reported that the underwriting cycle for non-life insurance industries of China was 4-5 years. Ji and Zheng (2009) used a second order autoregressive model and spectral analysis with gross ratio; they identified both long underwriting cycles of 12.516.7 years, and medium underwriting cycles of 5.6 years.

Wang and Shi (2006) and Ji and Zheng (2009) used same method, but came to opposite conclusions. This raised the question if the difference is due to the difference between a simple loss ratio and a gross ratio. If so, the cycle phenomenon on simple loss ratio and gross ratio will be consistent after excluding abnormal data. Differences between findings of $\mathrm{Li}$ and $\mathrm{Li}$ (2010) and Wang and Shi (2006) also raises the question if it was abnormal data in the underwriting cycle, invisible in second order autoregressive model, that led to their conclusions.

A second order autoregressive model with a structural transition is used here to analyze whether simple loss ratio time-series data exhibits a structural transition. It determines the reason for structural transition and introduces dummy variables at points in the structural transition to analyze the underwriting cycle of the property insurance industry in China. Taking into account that the lack of an underwriting cycle is caused by abnormal data in a simple loss ratio time-series, a ChristianoFitzgerald Filter was used to separate the trend and periodic components of simple loss ratio time-series one by one, and then to identify the existence of underwriting cycle of property insurance in China by use of a second order autoregressive model.

\section{Measure Methods on Underwriting Cycle}

Four methods are typically used to measure an underwriting cycle:

(1) Direct Observation. Direct observation uses some simple chart to express loss ratio data and operating profit data, the direction of chart or peak can be observed and used to judge the existence of an underwriting cycle and to estimate the length of the cycle. This method is most intuitive, but is also the most rough; thus, very few of applications rely on it because it is not possible to obtain an exact length of an underwriting cycle.

(2) Autoregressive Model. This method is applied widely and results in an exact length of an underwriting cycle by using a second order autoregressive model. Some researchers have identified the existence of structural transitions that caused the underwriting cycle to disappear and have shown that the structural transition, or presence of a transition, affects the test of an underwriting cycle and its length measurement (see Venezian, 1985; Cummins and Outreville, 1987; Chen, 1997; Leng, 2006). However, if dummy variables are introduced at a transition point, the length of the underwriting cycle can be obtained. This method can calculate the length of underwriting cycle and find the transition and its causes so that the phenomenon of the underwriting cycle can be understood. The downsides of this method are that data for analysis cannot be too short a time span and it cannot explain either the start or end points.

(3) Spectral Analysis. Spectral analyses were first used in physics, but have recently been employed to study economic cycles. These analyses can estimate economic cycles with shorter time series. Ji and Zheng (2009) used this approach to study underwriting cycles. This method has no requirement for data time-series and all data involved in the equation without losing the sample point. Because all data is placed into equations and there are clear calculation and process criteria, this approach can avoid subjectivity in analysis. However, this method results in different lengths of underwriting cycles for different data time-series even if the data comes from the same business line: Sometimes the difference is huge and the model cannot explain the difference. 


\section{ZHANG \& TANG}

(4) Christiano-Fitzgerald (CF) Filter Analysis. Filter analysis starts from time series volatility. It removes white noise from a time series and then obtains the regularity of its implied. This approach mainly used to study economic cycles and was used by $\mathrm{Li}$ and $\mathrm{Li}$ (2010) to study underwriting cycles. The method provides different results under different hypotheses for different filters. Generally, the CF filter is used to study economic cycles. CF filters can isolate trend and periodic components in time series data. Studying a periodic component can result in identifying an underwriting cycle with high credibility, but the chart cycle from this method has no higher credibility.

Each method has its own advantages and disadvantages. As an objective phenomenon, an underwriting cycle will have almost same length regardless of what method is used. This article uses a CF filter and second order autoregressive model with a structural transition to study the underwriting cycle of the property insurance industry in China.

\section{Methodology}

The Existence of an Underwriting Cycle: Indicators Selected and Data Resource

The best indicator is gross ratio or underwriting profit margin. Venezian (1985) used underwriting profit margin as the variable to test the existence of underwriting cycles in the property insurance industry in the United States. Gross loss ratio, or underwriting profit margin, arose in many references as an indicator of testing. Because there is no consistency of expense ratio in China, this study used a simple loss ratio, which is equal to ratio of losses and premiums. The gross loss ratio is equal to the simple loss ratio plus gross expenses ratio; because the expenses ratio is typically stable, a simple loss ratio can be substituted for the gross loss ratio. Data in this study is 1982-2008 property insurance collected from the China Insurance Yearbook and China Statistical Yearbook.
The Existence of an Underwriting Cycle: Stationary Test

It is first necessary to judge whether a time series is stationary both in the second order autoregressive model and the CF filter. A common test used for time series data is the Augmented Dickey-Fuller (ADF) test statistic; ADF analyzes the stationary of data and tests whether the data has unit root. Results of this test are shown in Table 1.

Table 1 shows a t-statistic equal to -1.110974 ; this result indicates that the null hypothesis cannot be rejected, thus, the timeseries data has unit root, which is not smooth. From this, it may be determined that outliers are present in the simple loss rate time series; for this reason, a dummy variable was introduced into the second order autoregressive model and analyzed by $\mathrm{CF}$ filter after treatment of abnormal values to conduct empirical analysis about the existence of underwriting cycle.

Empirical Analysis: Second Order Autoregressive Method

Next, the stability of loss rate timeseries is tested. The loss rate time-series is stability when autocorrelation and partial autocorrelation tests are used. Structural transition exists in loss rate time-series (Leng, 2002), but the exact point of transition is unknown, so the Chow Square Test is used to judge that point. Table 2 shows that the F-value is 5.023 , which is higher than the $1 \%$ level, and the LLR $=14.598$ in 1991. These are the largest in all results and they indicated the presence of an abnormal phenomenon in 1991; this is the structural transition.

Compared with the situation of the property insurance industry development in China in 1991, it is postulated that there may be two reasons for the s structural transition in that year. First, with increased competition in domestic market the loss rate increased. The insurance industry carried out an open policy in all of China in 1991, so more companies entered the insurance industry and competition increased. Insurance companies competed for market share and lower underwriting levels led to a surge of loss rate so that the loss rate after 1991 is significantly higher than before. Second, the American insurance market is a very 


\section{UNDERWRITING CYCLE OF PROPERTY INSURANCE INDUSTRY OF CHINA}

important market in the world; it has huge premiums, especially liability premiums. Chinese insurance companies possibly did not understand the coverage of American liabilities or the legislation associated with those liabilities, so Chinese companies may have assumed a large insurance liability blindly in world market in 1980s. In addition, Chinese insurance companies assumed a lot of claims of liability insurance in 1991 and ignored the characteristics of reinsurance claims lags at that same time.

Due to this, a dummy variable is introduced in a second order autoregressive model as:

$$
\begin{aligned}
C R(t)= & c+a C R(t-1)+b C R(t-2)+d D \\
& +e D C R(t-1)+f D C R(t-2)+u
\end{aligned}
$$

Using Eviews 6.0 (statistical software) for analysis results in the regression shown in Table 3.

After introducing the dummy variable (Table 3), $a>0$ and $b<0$ can be found; $a$ and $b$ are then used to calculate the underwriting cycle of the property insurance industry, which is 11.938 .

$$
\begin{aligned}
T & =\frac{2 \pi}{\cos ^{-1}(a / 2 \sqrt{-b})} \\
& =\frac{2 \pi}{\cos ^{-1}(0.862382 / 2 \sqrt{-(-0.340534)})} \\
& =11.938
\end{aligned}
$$

Empirical Analysis: CF Filter

Economic variables include trend, periodic and random components. If the trend and random components can be separated from the periodic component, the periodic component can be used to measure the cycle of an economic variable. Normally, the random component is ignored because it has little effect and the CF filter is used to separate the trend and periodic components and to analyze the periodic component (Table 4).

Use of a second order autoregressive

\begin{tabular}{|c|c|c|}
\hline & t-Statistic: & Prob.: \\
\hline Augrmented Dickey-Fuller test statistic & -1.110974 & D. 6950 \\
\hline $\begin{array}{cc}\text { Test critical walues: } & 1 \% \text { lewel } \\
5 \% \text { lewel } & 10 \% \text { level }\end{array}$ & $\begin{array}{l}-3.724070 \\
-2.986225 \\
-2.632604\end{array}$ & \\
\hline
\end{tabular}
model to test the periodic component results in

\begin{tabular}{|c|c|c|c|}
\hline Variable & $\mathrm{c}$ & $\mathrm{a}$ & $\mathrm{b}$ \\
\hline Coefficient & -0.00127 & 1.73261 & -0.96809 \\
\hline $\begin{array}{c}\text { Standard } \\
\text { Deviation }\end{array}$ & $6.80 \mathrm{E}-05$ & 0.008428 & 0.008202 \\
\hline t-Value & -1.86578 & 205.5874 & -118.076 \\
\hline $\mathrm{R}^{2}$ & \multicolumn{3}{|c|}{0.999643} \\
\hline
\end{tabular}

$$
\begin{aligned}
T & =\frac{2 \pi}{\cos ^{-1}(a / 2 \sqrt{-b})} \\
& =\frac{2 \pi}{\cos ^{-1}(1.732610 / 2 \sqrt{-(-0.968092)})} \\
& =11.720
\end{aligned}
$$

Table 1: ADF Test Output

*Mackinnon (1996) one-sided p-values. 


\section{ZHANG \& TANG}

Table 2: Chow Square Test - Structural Transition

\begin{tabular}{|c|c|c|c|c|}
\hline Year & F-value & Probability & LLR & Probability \\
\hline 1987 & 1.286 & 0.308 & 4.621 & 0.202 \\
\hline 1988 & 1.633 & 0.215 & 5.735 & 0.125 \\
\hline 1989 & $2.446^{*}$ & 0.095 & $8.164^{* *}$ & 0.043 \\
\hline 1990 & $2.901^{*}$ & 0.062 & $9.427^{* *}$ & 0.024 \\
\hline 1991 & $5.023^{* * *}$ & 0.010 & $14.598^{* * *}$ & 0.002 \\
\hline 1992 & $2.524^{*}$ & 0.088 & $8.386^{* *}$ & 0.039 \\
\hline 1993 & $2.981^{*}$ & 0.057 & $9.643^{* *}$ & 0.022 \\
\hline 1994 & $3.329^{* *}$ & 0.042 & $10.56^{* *}$ & 0.014 \\
\hline 1995 & 1.599 & 0.223 & 5.627 & 0.131 \\
\hline 1996 & 1.954 & 0.155 & $6.723^{*}$ & 0.081 \\
\hline 1997 & 0.986 & 0.420 & 3.619 & 0.306 \\
\hline 1998 & 0.352 & 0.788 & 1.351 & 0.717 \\
\hline 1999 & 0.541 & 0.660 & 2.049 & 0.562 \\
\hline 2000 & 0.508 & 0.681 & 1.930 & 0.587 \\
\hline 2001 & 0.424 & 0.738 & 1.618 & 0.655 \\
\hline 2002 & 0.729 & 0.547 & 2.723 & 0.436 \\
\hline 2003 & 1.177 & 0.345 & 4.262 & 0.235 \\
\hline 2004 & 1.370 & 0.282 & 4.895 & 0.180 \\
\hline 2005 & 1.361 & 0.285 & 4.867 & 0.182 \\
\hline 2006 & 1.282 & 0.309 & 4.609 & 0.203 \\
\hline
\end{tabular}

*Means 10\% level, **Means 5\% level, ***Means 1\% level. Structure transition is in 1991.

Table 3: Regression Analysis Table - Introduced Dummy Variable

\begin{tabular}{|c|c|c|c|c|}
\hline Variable & Coefficient & $\begin{array}{c}\text { Standard } \\
\text { Deviation }\end{array}$ & t-Value & $\mathrm{R}^{2}$ \\
\hline $\mathrm{c}$ & 0.155 & 0.165 & 0.935 & \multirow{6}{*}{0.669} \\
\hline $\mathrm{a}$ & 0.862 & 0.487 & 1.771 & \\
\hline $\mathrm{b}$ & -0.249 & 0.497 & -0.500 & \\
\hline $\mathrm{d}$ & 0.278 & 0.209 & 1.330 & \\
\hline $\mathrm{e}$ & -0.968 & 0.534 & -1.814 & \\
\hline $\mathrm{f}$ & 0.540 & 0.534 & 1.012 & \\
\hline
\end{tabular}




\section{UNDERWRITING CYCLE OF PROPERTY INSURANCE INDUSTRY OF CHINA}

\section{Conclusion}

The existence of a structural transition in 1991 in the Chinese property insurance industry is verified by using simple loss rate data. A second order autoregressive model and CF filter were also used to calculate the underwriting cycle of the $\mathrm{P} \& \mathrm{C}$ insurance industry in China; the cycles are approximately 12 years in length. At the end of the paper, we give two suggestions to underwriting cycle management. Because the phenomenon of underwriting cycles is a risk factor, it is necessary to strengthen the management of underwriting cycles to lower their influence of volatility on the insurance business. Two strategies are suggested.

Recommendations for Underwriting Cycle Management

(1) Procyclical Policy: This policy's target is to maintain the market shares of insurance companies. At the very stage, the underwriting strategy will be maintained, regardless of changes in prices. The internal management of insurance companies may lead to increased cycle phenomenon and also to increased procyclical leverage effects. Insurance companies need to analyze all kinds of risks in operating procedures and allow a limit fluctuation.

(2) Countercycle Policy: This policy's target is to maintain the profitability of insurance companies. Insurance companies need to reduce their business line in soft market and only keep some profitable businesses so that they will have sufficient capital and surplus to expand in hard market.

\section{References}

Boor, J. (2000). The impact of the insurance economic cycle on insurance pricing. CAS study note. http://casualtyactuaries.com/library/studynotes/b oor5.2.pdf.

Venezian, E. (1985). Ratemaking methods and profit cycles in property and liability insurance. Journal of Risk and Insurance, 52, 477-500.

Cummins, \& Outreville. (1987). An international analysis of underwriting cycles in property-liability insurance, Journal of Risk and Insurance, 54, 246-262.

Ernst \& Young. (2009). Annual report of insurance industry operating risk in China market. http://www.ey.com/Publication/ vwLUAssets/Business_Risk_Insurance_Report_ 2009_Chinese/\$FILE/Business\%20Risk_Insuran ce_Report_2009_Chinese.pdf

Ji, Y., \& Zheng, H. (2009). Existence analysis of underwriting cycle of $\mathrm{P} \& \mathrm{C}$ insurance industry of China. Journal of University of Aeronautics and Astronautics, 22(4), 1-3.

Leng. C-C. (2006). Stationarity and stability of underwriting profits in propertyliability insurance: Part II. Journal of Risk Finance, 1, 49-63

Li, X., \& Li, J. (2010). Study on underwriting cycle of $\mathrm{P} \& \mathrm{C}$ insurance industry of China. Insurance Studies, 2, 44-52.

Qiujie, C. (2005). The general characteristics and reasons of interaction between insurance supply and demand. Journal of Jiangxi Finance University, 39, 33-37.

Wang, B., \& Shi, A. (2006). Study on underwriting cycle of $\mathrm{P} \& \mathrm{C}$ insurance industry and test in China market. Shanghai Finance, 7, $37-40$

Zhang, L., \& Zhu, Y. (2007). Existence analysis of auto insurance underwriting cycle of China. China Economical Review, 69, 66-70. 
Table 4 Trend and Periodic Component Filter Table

\begin{tabular}{|c|c|c|c|c|c|}
\hline Year & $\begin{array}{c}\text { Trend } \\
\text { Component }\end{array}$ & $\begin{array}{c}\text { Periodic } \\
\text { Component }\end{array}$ & Year & $\begin{array}{c}\text { Trend } \\
\text { Component }\end{array}$ & $\begin{array}{c}\text { Periodic } \\
\text { Component }\end{array}$ \\
\hline 1982 & 0.43178 & 0.023206 & 1996 & 0.55212 & 0.025064 \\
\hline 1983 & 0.46395 & 0.026539 & 1997 & 0.53744 & 0.019601 \\
\hline 1984 & 0.4877 & 0.023344 & 1998 & 0.56252 & 0.009925 \\
\hline 1985 & 0.4252 & 0.014245 & 1999 & 0.53197 & -0.00145 \\
\hline 1986 & 0.41764 & 0.001426 & 2000 & 0.51837 & -0.01179 \\
\hline 1987 & 0.39252 & -0.01192 & 2001 & 0.50494 & -0.01881 \\
\hline 1988 & 0.40884 & -0.02244 & 2002 & 0.53785 & -0.02118 \\
\hline 1989 & 0.43324 & -0.02749 & 2003 & 0.56653 & -0.01878 \\
\hline 1990 & 0.41533 & -0.02584 & 2004 & 0.52721 & -0.01254 \\
\hline 1991 & 0.51941 & -0.01797 & 2005 & 0.54965 & -0.0042 \\
\hline 1992 & 0.46525 & -0.00592 & 2006 & 0.52357 & 0.004285 \\
\hline 1993 & 0.48249 & 0.007262 & 2007 & 0.49964 & 0.011113 \\
\hline 1994 & 0.55175 & 0.018337 & 2008 & 0.6019 & 0.015071 \\
\hline 1995 & 0.41103 & 0.024713 & & & \\
\hline
\end{tabular}

